\title{
Reflections of Medical Students on Visiting Chronically Ill Older Patients in the Home
}

\author{
Jacqueline K. Yuen, BA, ${ }^{*}$ Risa Breckman, LCSW, ${ }^{\dagger}$ Ronald D. Adelman, MD, ${ }^{\dagger}$ Carol F. Capello, PhD, ${ }^{\dagger}$ \\ Veronica LoFaso MD, RN, ${ }^{\dagger}$ and M. Carrington Reid, $\mathrm{PhD}, \mathrm{MD}^{\dagger}$
}

The expanding number of Americans living with chronic illness necessitates educating future physicians about chronic illness care. Weill Cornell Medical College's Chronic Illness Care in the Home Setting Program (CIC-HSP), a mandatory part of the primary care clerkship, exposes medical students to persons with chronic illness via a half day of house calls with a geriatrics team. The investigators sought to qualitatively assess the effect of the CIC-HSP on medical students and recent medical graduates. Fifty-two prospective participants were approached, and 50 (96\%) with varying training levels and time since completing the program were interviewed.

Most respondents $(63 \%)$ found that the home visits taught them important approaches to caring for the chronically ill, such as individualizing care to meet patients' individual needs and improving quality of life as a goal of care. Students remarked that the experience enhanced their empathy $(18 \%)$ and sensitivity $(20 \%)$ toward chronically ill patients and increased their appreciation for chronic illness care $(35 \%)$. Many participants reported that patients were more empowered in the home $(55 \%)$ and perceived greater rapport and warmth between the doctor and patient $(57 \%)$ in the home (vs office) setting. The vast majority of recent medical graduates $(84 \%)$ related that this educational exposure continued to positively influence their approach to patient care.

A home visit experience with a geriatrics team can help foster medical students' understanding of the psychosocial and medical aspects of chronic illness, teach relevant approaches to patient care, and improve students' attitudes toward caring for the chronically ill. J Am Geriatr Soc 54:1778-1783, 2006.

Key words: geriatric education; home visits; chronic illness care

From the *University of Michigan Medical School, Ann Arbor, Michigan; and ${ }^{\dagger}$ Division of Geriatrics and Gerontology, Weill Medical College, Cornell University, New York, New York.

Address correspondence to Dr. M. Carrington Reid, Division of Geriatrics and Gerontology, Weill Medical College, Cornell University, 525 East 68th Street, Box 39, New York, NY 10021. E-mail: mcr2004@med.cornell.edu

DOI: $10.1111 / \mathrm{j} .1532-5415.2006 .00918 . x$
$M$ ore than 133 million persons living in the United States have a chronic illness, and this number will increase in the coming decades. ${ }^{1}$ To effectively address the needs of these individuals, physicians and other healthcare professionals must have knowledge about and skills in chronic illness care. Currently, most medical schools inadequately teach this important subject to medical students. ${ }^{2,3}$ Clinical training programs continue to employ the traditional acute-care model, in which instruction occurs primarily in the inpatient setting. As a result, medical students lack opportunities to engage in and learn about chronic illness care. In addition, medical students can develop negative attitudes about caring for patients with chronic illnesses as their clinical experience with this patient population increases. ${ }^{4-7}$

In response to the above deficiencies, geriatrics faculty at Weill Cornell Medical College (WCMC) developed and implemented the Chronic Illness Care in the Home Setting Program (CIC-HSP). This program is part of a required 6week primary care clerkship, which all WCMC medical students participate in during their third or fourth year of training. During the CIC-HSP, each student goes on a half day of house calls with a geriatrics team. By observing a healthcare team in action, students witness the physical and psychosocial effect of disease on patients' lives in a personalized context and learn about patient-provider partnerships and chronic illness care management.

This study used qualitative research methods to assess the effect of the home visitation program on medical students and recent medical graduates and to determine whether the program positively influenced medical graduates' approach to patient care over time.

\section{METHODS}

\section{Sample Assembly}

A stratified sample was assembled and included students from the class of 2006 and graduates from the classes of 2005 and 2004. Prospective participants were first notified about the study via e-mail. One investigator (JY) then attempted to contact prospective participants via telephone with the goal of obtaining roughly equal numbers of respondents in each class. The total number of students per class, the number successfully contacted by phone, and the 
number who agreed to be interviewed is as follows: $101 / 19 /$ 19 (class of 2006), 88/16/16 (class of 2005), and 110/17/15 (class of 2004). The overall participation rate was 50 of 52 $(96 \%)$. All interviews were conducted between July and September 2006. The local institutional review board approved the study.

\section{Description of Educational Exposure(s)}

The students accompanied the house-call team, which in almost all cases consisted of a geriatrician, nurse practitioner, and geriatrics fellow, on their routine home visits. The patients that students visited were not selected for any particular characteristics (e.g., disease process, functional or cognitive status). Because the patients in the house-call program were homebound, the students did not have the opportunity to see patients before the visit. All participants in the current study made at least one home visit (average duration $45 \mathrm{~min}$ ) and $90 \%$ went on two or more visits.

As part of the CIC-HSP, students also complete a creative project that requires them to express their personal thoughts, feelings, and reactions to the home visits using a creative medium such as artwork, music, or narrative. Students present their projects during a mandatory class seminar that reinforces important themes in chronic illness care and is facilitated by an interdisciplinary geriatrics faculty (i.e., a social worker and physician). Students are encouraged to focus less on the medical information and to highlight their reactions to the visit from a personal viewpoint.

Although the CIC-HSP constitutes a core component of WCMC's primary care clerkship, students have outpatient experiences in other disciplines as well (e.g., medicine, family medicine, emergency department/urgent care). These experiences provide students with additional exposures to managing chronic disease, self-management approaches to care, and eliciting psychosocial histories.

\section{Data Collection}

To assess the effect of the house-call experience, the investigators developed an interview questionnaire that included the following open-ended questions: "What if anything is different about the doctor-patient interaction in the home versus the office setting?" "What did you learn about caring for chronically ill patients from the home visit?" "How did the home visitation program affect your attitude toward caring for chronically ill patients?" "What feelings did going on the home visits evoke?" One additional question, "In what way did you find the program had an impact on how you deliver patient care?" was asked of the 2004 and 2005 graduates to ascertain whether the program had any longterm influence on their approach to care. Finally, information on participants' demographic status and intended specialty was also obtained.

The interview took, on average, 15 minutes to complete. One investigator (JY) conducted all of the interviews in person or over the telephone. All interviews were audiotaped and transcribed.

\section{Data Analysis}

Descriptive statistics were calculated for the quantitative questions. For the qualitative component of the study, two investigators (JY, RB) independently reviewed transcripts of participants' responses to the open-ended questions, and recurring responses were coded as distinct themes. ${ }^{8,9}$ The investigators then met to compare the coded responses and reach consensus on any conceptual differences. The transcribed data were reviewed on several occasions to ensure that all unique responses had been identified and suitably classified. Finally, to help facilitate a more conceptual understanding of the identified themes, the investigators grouped the themes into discrete domains using a consensus approach.

\section{RESULTS}

Participants $(\mathrm{n}=50)$ had a mean age \pm standard deviation of $27 \pm 3$ (range $=24-40)$. Twenty-eight $(56 \%)$ participants were female; 26 (52\%) were Caucasian, $10(20 \%)$ were African American, eight (16\%) were Asian American, and six $(12 \%)$ reported other races/ethnicities. Participants voiced a preference for practicing in medicine/pediatrics $(42 \%)$, surgery/anesthesiology $(32 \%)$, or other specialties $(13 \%)$. The themes that emerged from the open-ended questions are reported below and summarized along with additional illustrative quotes in Tables 1-3.

\section{The Doctor-Patient Interaction in the Home Setting}

Table 1 shows the major differences participants reported about the doctor-patient interaction in the home (vs office) setting. One commonly mentioned difference was a power dynamic shift in the patient's home versus the doctor's office and its effect on the doctor-patient relationship. Many respondents emphasized the geriatrician's positive traits, which included empathy and patience when relating to the patient in the home setting, as well as the geriatrician's role as a team member. A common perception was that patients were comfortable interacting with the physician at home. Many respondents cited patients' appreciation of the doctor's visit, recognizing that this visit was the highlight of their day. One student commented:

I saw this doctor being a lot more patient than she would be in an office setting. There was a bigger chunk of time given to the patient than what would have been allowed in an office visit. It seemed like the doctor was made aware of more issues than she would have in an office setting. This patient was living in a decrepit apartment, and she [the physician] focused a lot on helping the patient think about more services and trying to convince her that more services could help. I don't know if the doctor would have emphasized this as much if she had seen her in the office. I think there's probably also a mental health component to it. She might have been depressed. Seeing how she was living helped to give the doctor clues about what was actually going on.... The healthcare team let the patient take more of the lead in the interaction. They're not on their territory, they're on the patient's territory, and they have to be more respectful of the patient's environment and what she wants.

\section{Lessons on Caring for Chronically Ill Patients}

Table 2 shows important lessons that participants took away from the home visits about caring for those with chronic illness. Making home visits was valued as an approach that allowed physicians to better assess patients' needs and the effect of interventions on their lives. Re- 
Table 1. Doctor-Patient Interaction in the Home Versus Office Setting

\begin{tabular}{|c|c|c|}
\hline Domain & $\begin{array}{c}\text { Theme (\% of Subjects Who } \\
\text { Reported This Theme) }\end{array}$ & Illustrative Quotes \\
\hline \multirow[t]{3}{*}{$\begin{array}{l}\text { Doctor-patient } \\
\text { relationship }\end{array}$} & Power dynamic shift (55) & $\begin{array}{l}\text { "There's definitely a shift in power when you're coming into these people's } \\
\text { homes. Although you have to be on your toes and not exert the power as you } \\
\text { would have in the office, it's still something that really empowers the physician } \\
\text { because you build up a connection with a patient that is incredibly unique." } \\
\text { "We were on his (the patient's) turf. I think the tone was set more by him. It } \\
\text { wasn't the standard sort of factory mill that the doctor's office can be. The care } \\
\text { centered around his life and accommodated to his circumstances." }\end{array}$ \\
\hline & $\begin{array}{l}\text { Quality of interpersonal } \\
\text { relationship (57) }\end{array}$ & $\begin{array}{l}\text { "The doctors were not wearing their white coats, so it felt like a friendly } \\
\text { interaction. They were able to interact in a more complete way by talking } \\
\text { about other things that may be impacting the patient other than the medical } \\
\text { condition." }\end{array}$ \\
\hline & Quality of communication (60) & $\begin{array}{l}\text { "There was no time pressure at all. The doctor was there to answer all of their } \\
\text { questions. Even though a lot of the questions were directed at the doctor, I } \\
\text { really feel the doctor was part of the team, and there were other people who } \\
\text { had an equal, if not greater, role in the patients' care." }\end{array}$ \\
\hline $\begin{array}{l}\text { Physician } \\
\text { characteristics }\end{array}$ & Geriatrician trait (24) & $\begin{array}{l}\text { "The physician I went with was very sincere in her caring. She was just very } \\
\text { empathic and concerned and united with the patient." }\end{array}$ \\
\hline $\begin{array}{l}\text { Patient } \\
\text { characteristics }\end{array}$ & $\begin{array}{l}\text { Patient at ease, comfortable } \\
\text { (34) }\end{array}$ & $\begin{array}{l}\text { "It all seemed a little bit more humane, a little more caring. I guess because } \\
\text { you're in someone else's space, you're on their turf as opposed to them } \\
\text { coming to you. It feels completely different. It's a lot more comfortable for the } \\
\text { patient." }\end{array}$ \\
\hline
\end{tabular}

spondents recognized the important ways in which psychosocial issues affect patients' quality of life and how patients cope with these concerns. It also highlighted the central role of the caregivers and family members and raised awareness about caregiver stress. For many participants, the effect of the home environment on the patient's functionality and ability to comply with treatment plans became evident. As noted by one respondent:

\begin{abstract}
When you go into somebody's home, you really see how they are living. I think it's important a lot of times to see somebody in their own setting to see what sort of obstacles they are dealing with, and especially for older people, it's important to know their home environment, because they may be falling and sustaining injuries if they don't have good lighting in their house.... When you go to their homes, you get to meet the aides, and those people are so important for the care of the elderly people, who depend on them a lot. They sometimes can tell you more than the patient can.
\end{abstract}

\section{Effect on Attitudes Toward Caring for the Chronically Ill}

Table 3 reflects the different ways in which the home visit program influenced participants' attitudes toward caring for chronically ill patients. Key themes included increased empathy and respect for patients with chronic illness and increased sensitivity to their needs as individuals. Several respondents reported that seeing patients in the home setting helped break down stereotypes they held about older patients, as illustrated by this comment.

Patients with a long list of problems are very intimidating. I know that in the past I felt that I just didn't want to deal with that kind of patient. I think the experience made me see things differently. It allowed me to see them not just as a problem list but as wise people who still have a lot to give, even though their list of meds is as long as my arm.
Many participants developed a greater appreciation for chronic illness care. Some recognized how rewarding it may be to help older patients continue to lead full lives despite their medical condition, whereas others were able to see chronic illness in a more important light. One respondent described the effect of the home visit experience this way:

It was a great educational experience. You realize that patients can be at home sometimes and you realize that there is potential for healing at home. Being in the hospital and on the floors all the time, that's not what you see. ... The experience helped me appreciate the complexity of chronic disease because of all the conditions they might have and the various problems that are associated with the conditions. It gave me a more positive outlook on the field of geriatrics.

\section{Feelings Evoked by the Home Visits}

Participants reported a wide range of responses to the question about what feelings were evoked as a result of the home visit experience. The most common response was sadness $(33 \%)$ due to seeing the patient's deteriorated condition. Other feelings included appreciation for the opportunity to see patients outside of the hospital setting $(17 \%)$, empathy toward homebound patients $(17 \%)$, gratitude for the good care and support that patients receive $(16 \%)$, and nostalgia when the experience prompted them to think about personal experiences such as dealing with their own families $(12 \%)$.

\section{Effect on Approach to Patient Care}

Most class of 2004 (87\%) and 2005 (81\%) graduates described one or more ways that the home visit program positively influenced their delivery of patient care. For example, the experience improved their sensitivity to the needs of the patient as a whole person $(23 \%)$, reinforced the 
Table 2. Lessons on Caring for Chronically Ill Patients

Theme $(\%$ of Subjects Who

Domain Reported This Theme)

Illustrative Quotes

Geriatric
psychosocial issues

Effect of chronic illness on

patient and family (31)

"It's good to be mindful of how much of a burden it can be (living with chronic Central role of caregivers and "I appreciated how daunting it is to take care of a patient at home. It's really a social support (16)

$24 / 7 \mathrm{job}$, and a lot of times we take these things for granted in the hospital and don't realize that, even after they go home, they still need a lot of care and it's really taxing on the caregiver."

Home environment Effect of home environment on "There's no way you can deal with specific home issues like how many stairs awareness health (36) they have or if they have carpets that slip. It's hard to remember all of the things to ask about when they're in your office, whereas a picture is worth a thousand words. When you're in their setting, a lot of things immediately become clear."

"Both of the patients I visited could have gotten more aggressive treatment and neither was inclined to want that. By being at home it made them easier to deny care, and it made it easier for us as medical professionals to see it may not be the best things medically, but it may be the best thing for the person."

Managing chronic illness

Relevant approaches to interventions (63)

Relevant approaches to patient communication (36) "It's easy to say for something like arthritis to think only about the medication or, if the patient only has a low level of pain ( 3 out of 10) and it was 8 a couple of weeks ago, you would think, 'Oh that's great, my job is done.' But if you see them in their home and you see what a 3 out of 10 means, you might think, 'Oh, well, I have more to do here."'

"It is not just the pathophysiology of the disease process, but also the social details that are so important to a person's quality of life. The experience really showed me how important ancillary caregivers are and ensuring that the patient has them."

"I learned to really build rapport with the patient because the faster you build rapport, the faster you might be able to pick up on depression or other nonphysical factors. All these personal details can really help you in serving the patient." importance of taking a good social history $(23 \%)$, and emphasized the need to build rapport with patients $(10 \%)$. One graduate described the lasting effect of the home visits as follows:

It made me spend a few days thinking about the way that one can approach patients and how best to build rapport.... Any time that you stop medical school and think about those kinds of things is a beautiful moment. It happened a long time ago, and I actually do still think about it from time to time as a really memorable experience.

Furthermore, the program taught graduates to think more comprehensively about patients' needs in discharge planning $(35 \%)$, such as ensuring that patients are discharged to safe environments. Participants frequently reported that they were reminded of lessons learned from their home visit experience and applied these lessons in their work as interns or residents. As one respondent noted:

I'm more cognizant of older patients' support systems, what their home situation is like, and making sure that they have a safe discharge plan. Sending them home may not be okay because of their home environment. One specific thing that I remember... there was an elderly woman who came into the neurology service who was found by her doorman and no one knew anything about her. I actually went with one of the medical students to her apartment to find out more information, and I was thinking of the home visit experience. Her apartment was a complete mess, and there were probably a whole lot of other psychosocial things going on with her before her coming in with a stroke. ... If a physician had come to her home and seen the way she was living, maybe everything that subsequently happened could have been prevented.

For class of 2004 and 2005 graduates pursuing training in medicine or pediatrics, surgery or anesthesiology, or other specialties (e.g., psychiatry, emergency medicine), the number of respondents who indicated at least one way that the home visit experience positively affected their delivery of patient care was compared. The relative proportions were medicine/pediatrics $(12 / 14 ; 86 \%)$, surgery/anesthesia $(5 / 7 ; 71 \%)$, and other specialties $(8 / 10 ; 80 \%)$. The differences were not statistically significant $(P=.61)$. The results indicate that most graduates, irrespective of selected medical specialty, felt the home visit program had a positive influence on their delivery of patient care.

\section{Other Relevant Findings}

Several respondents specifically mentioned the significant contributing role of the creative project and class seminars in the course. One respondent commented:

I don't know if I'd remember as much telling you about it now if I hadn't gone home and written about it for the class presentation. 
Table 3. Effect of Home Visits on Attitude Toward Caring for Chronically Ill Older Patients

Theme $(\%$ of Subjects Who
Domain $\quad$ Reported This Theme)

Illustrative Quotes

Attitude toward geriatric patients geriatric medicine
Increased empathy and respect "It made me appreciate how a patient can live with a chronic disease seeing for patients coping with chronic them deal with this every day. I think it improved my empathy towards the illness (18) Increased sensitivity to patients' "It'll give me the perspective to be more comprehensive in terms of thinking needs as individuals (20) Broke down stereotypes and stigma of older patients (11)

See rewards in caring for patients with chronic illness about their issues and trying to help provide the resources that they need." "When you see somebody who is demented and can't really communicate, you just don't get a sense of what the person's like. But when you're in their house and you get to see the sorts of things they have done with their lives, you get a sense of the person that is trapped inside that dementia."

"I think more than anything, it's affected my attitude in that I'm less anxious about feeling emotionally invested in patients."

"Prior to this experience, I thought it would be something that wouldn't be rewarding because you wouldn't have a problem that you can actually fix. But now I realize that helping people to cope and being there to support them was something valuable and rewarding."

See chronic illness in a more "There used to be a part of me thinking to myself, why are we spending so many resources on someone who is so debilitated? One thing that I learned during the visits is that these folks still have something to bring to society." important light (11)

Revealed challenges of chronic illness care (14)
"At no fault of the program itself, I don't think I have the strength to take care of a chronically ill patient. I think it would take a certain amount of character. I think I would be too saddened, but I have great respect for those who do it."
It was a way to cement the memory and to process more of what I learned and the feelings I had about the visits.

Another respondent discussed how the presentations rounded out her experience:

It was very informative to hear other people's presentations. I felt that by talking about what we saw and how we felt about it, it was as if we had seen more of it. I think a lot of us had some fears and some delights. It was appropriate to have a forum to share our feelings with other students who also went on home visits. I think it would be a real mistake to do the home visits and not have that kind of outlet.

\section{DISCUSSION}

This investigation documents the effect of the home visit experience in the words of the participants themselves. To the authors' knowledge, this is the first study to evaluate the effect of a chronic illness care home visit program on medical students and recent medical graduates over time. ${ }^{10-13}$

The most prominent theme that emerged regarding students' perceptions of the physician-patient communication in the home setting was a power dynamic shift between the doctor and the patient. Participants frequently reported that patients were empowered when medical care was provided in their own homes, as evidenced by increased patient expressiveness and assertiveness when discussing care issues with their physicians, ${ }^{14}$ and that this helped build doctorpatient rapport and served as a foundation for meaningful doctor-patient communication. A previous study identified medical practitioners' loss of control in the home as a pervasive theme in examining the interactions between medical students and their patients. ${ }^{12}$ This investigation reported that relinquishing control to the patient allowed important information on the psychosocial effect of disease on the patient to be communicated, which in turn allowed physicians to better manage patients' chronic illnesses.

The presence of the geriatrics team was another significant aspect of the home visit program. Participants frequently commented on the caring quality and effectiveness of the healthcare professionals they observed on the visits. The geriatrician was viewed as a role model for delivering effective chronic care management, including overseeing care in a multidisciplinary team effort. For example, the geriatrician frequently made referrals to community-based social workers or visiting nurses to provide crucial services, such as in-home meals, care management, or in-home psychotherapy.

Seeing patients in their home environments surrounded by mementos of their life history helped students to better realize the personhood of these patients. Students witnessed the effect of disease on patients' lives and understood the importance of a safe home environment and adequate social support. Although a span of 2 years had passed since some of the graduates completed the program, they reported having vivid memories of the patients they had seen and continued to apply the lessons learned when caring for patients. For example, many graduates emphasized the importance of discussing issues regarding the patient's home environment with patients and their caregivers, as well as involving ancillary services such as social workers and physical therapists in their management.

Many respondents thought the home visit experience improved their attitude toward older, chronically ill patients and increased their sensitivity to the needs of these patients as individuals. However, the response was mixed as to the effect the experience had on their attitude toward 
providing care to this patient population. Although many respondents saw that caring for the chronically ill was an important task and one that could be rewarding, others did not desire to care for that patient population, because they wanted curing disease to be the focus of their future patient care.

This study has several limitations. First, it is unclear to what extent the positive effect of the home visit experience on the students' attitudes can be attributed to their observations and interactions with the patients versus their interactions with the highly qualified healthcare professionals on the house-call team. Second, a relatively small number of students from three different medical school classes was surveyed. Although the response rate (number of students enrolled/number successfully contacted by phone) in the current study was substantial, it is possible that students not contacted by phone may have had different perceptions and attitudes about the home visit experience. Finally, although the class seminars also likely contributed to the positive outcomes associated with the CIC-HSP experience, this study did not examine the specific influence of the seminars.

Despite these limitations, the qualitative nature of this study captured the full range of students' perceptions about the home visits in the context of their experiences. Significant themes that resonated with many of the respondents were identified. In addition, although the home visit experience was a "single" exposure, the students' experience was magnified by presentations of their colleagues during the seminars.

In conclusion, this study identified a substantial positive effect of a home visit program on students' attitudes and approaches to patient care. Using a home visit experience as a vehicle for teaching chronic illness care has promising longitudinal influences.

\section{ACKNOWLEDGMENTS}

We gratefully acknowledge the help of Elise Cummings for transcription services.

Financial Disclosure: This work was supported by the Adolph and Ruth Schnurmacher and Donald W. Reynolds Foundations, the American Federation for Aging Research Medical Student Summer Research Training in Aging Program (Yuen), the Edward R. Roybal Center Grant from the
National Institute on Aging (Breckman, Reid), the John A. Hartford Foundation (Reid), and the Paul Beeson Physician Faculty Scholar in Aging Research Award (Reid).

Author Contributions: Jacqueline Yuen: study concept and design, acquisition of subjects and data, analysis and interpretation of data, and preparation of manuscript. Risa Breckman and M. Carrington Reid: study concept and design, analysis and interpretation of data, and preparation of manuscript. Ronald Adelman, Carol Capello, and Veronica LoFaso: study concept and design and preparation of manuscript.

Sponsor's Role: None.

\section{REFERENCES}

1. Partnership for Solutions. Chronic Conditions: Making the Case for Ongoing Care (September 2004 Update). Johns Hopkins University for the Robert Wood Johnson Foundation [on-line]. Available at www.partnershipforsolutions.com/dms/files/chronicbook2002.pdf Accessed February 20, 2006.

2. Pham HH, Simonson L, Elnicki DM et al. Training U.S. medical students to care for the chronically ill. Acad Med 2004;79:32-40.

3. Cohen AJ. Caring for the chronically ill: A vital subject for medical education. Acad Med 1998;73:1261-1266.

4. Davis BE, Nelsen DB, Sahler OJ et al. Do clerkship experiences affect medical students' attitudes toward chronically ill patients? Acad Med 2001;76:815820 .

5. Marple RI, Pangaro I, Kroenke K. Third-year medical students' attitudes toward internal medicine. Arch Intern Med 1994;154:2459-2464.

6. Griffith CH III, Wilson JF. The loss of student idealism in the 3rd-year clinical clerkships. Eval Health Prof 2001;24:61-71.

7. Fitzpatrick SB, O'Donnell R, Getson P et al. Medical students' experiences with and perceptions of chronic illness prior to medical school. Med Educ 1993;27:355-359.

8. Strauss A, Corbin J. Basics of Qualitative Research. Techniques and Procedures for Developing Grounded Theory. Thousand Oaks, CA: Sage Publications, 1998.

9. Miles MB, Huberman AM. Qualitative Data Analysis: An Expanded Sourcebook. Thousand Oaks, CA: Sage Publications, 1994.

10. Fried VA. Teaching geriatric assessment in home visits: The family physician/ geriatrician attachment. Teach Learn Med 2003;15:123-126.

11. Medina-Walpole A, Heppard B, Clark NS et al. Mi casa o su casa? Assessing function and values in the home. J Am Geriatr Soc 2005;53:336342 .

12. Sankar A. Out of the clinic into the home: Control and patient-physician communication. Soc Sci Med 1986;22:973-982.

13. Sankar A, Becker S. The home as a site for teaching gerontology and chronic illness. J Med Edu 1985;60:308-313.

14. LoFaso V. The doctor-patient relationship in the home. Clin Geriatr Med 2000;16:83-94. 